\title{
Preenchimento de unidades prosódicas na aquisição fonológica inicial do português brasileiro
}

\author{
Prosodic unit completion within the early phonological acquisition of Brazilian Portuguese
}

\author{
Luzia Miscow da Cruz Payão \\ Universidade Estadual de Ciências da Saúde de Alagoas - Maceió - Alagoas - Brasil \\ Januacele Francisca da Costa \\ Universidade Federal de Alagoas - Maceió - Alagoas - Brasil
}

\begin{abstract}
Resumo: Investigou-se a influência do acento e o preenchimento segmental de unidades prosódicas em dados de fala de duas crianças entre 1;0.4 e 2;1.10 de idade, expostas ao PB falado em Alagoas e Pernambuco. Partiu-se da hipótese de processamento gramatical de direções opostas co-ocorrentes: a centrípeta segmentando a sílaba proeminente e a oposta, centrífuga, destinada aos preenchimentos segmentais das unidades prosódicas. Nas análises está implícita a hierarquia entre as estruturas constituintes, preconizada pelas fonologias autossegmental (GOLDSMITH, 1995; CLEMENTS; HUME, 1995; MOTA, 1996) e prosódica (NESPOR; VOGEL, 1986; SCARPA, 1997, 1999a; SANTOS; SCARPA, 2005). O predomínio de palavras com o padrão de acento troqueu contribuiu para o preenchimento da estrutura silábica e a diferenciação de classes segmentais na sílaba tônica e na pós-tônica, embora o preenchimento tenha ocorrido de forma semelhante nas sílabas pré e pós-tônicas sob influência do pé métrico da palavra-alvo.
\end{abstract}

Palavras-chave: Aquisição fonológica; Prosódia; Sílaba; Segmento

\begin{abstract}
The study looked into the influence of accent and segment completion of prosodic units in speech data from two children aged between 1;0.4 and 2;1.10 who had been in contact with BP spoken in Alagoas and Pernambuco. Early hypothesis was that grammatical processing occurred in simultaneous opposite directions: centripetal motion triggering segmentation of the prominent syllable and an opposite centrifugal motion causing segment completion of prosodic units. The analyses imply a hierarchical organization of its constituent structures, an assumption backed by autosegmental (GOLDSMITH, 1995; CLEMENTS; HUME, 1995; MOTA, 1996) and prosodic phonology (NESPOR; VOGEL, 1986; SCARPA, 1997, 1999a; SANTOS; SCARPA, 2005). The prevalence of words having a trochaic stress pattern contributed to syllable structure completion and distinction of segment classes in stressed and post-tonic syllables, although completion in post-tonic and pre-tonic syllables had occurred according to the metrical foot of the target word.
\end{abstract}

Keywords: Phonological acquisition; Prosody; Syllable; Segment

\section{Introdução}

A aquisição fonológica preconizada no presente estudo origina-se da gramática universal, centrada na competência do falante e na marcação de parâmetros a partir do input. De acordo com o gerativismo, o contato com uma língua natural dispara o dispositivo inato da Faculdade de Linguagem (FL) capaz de processar a aquisição da língua materna. Adota-se neste trabalho a visão gerativa do Programa Minimalista (PM) de Chomsky (1995) - traduzida por Eduardo Paiva Raposo
(1999, p. 24 - tradução, apresentação e notas à tradução), que pressupõe a FL como:

\footnotetext{
Enquanto sistema expressivo, FL é um sistema 'exteriorizante', associado a um sistema de produção e a um sistema de recepção, de natureza sensorial e/ou motora (envolvendo organizações neuronais, músculos, e outros órgãos anatômicos parcialmente adaptados à exteriorização lingüística, como a língua, o ouvido, a laringe, etc.). No lado da produção, temos tipicamente um sistema vocálico-articulatório, e no lado da recepção, temos (também tipicamente) um sistema de percepção, neuro-auditivo (CHOMSKY, 1999, p. 24).
} 
A hipótese preliminar investigada no presente estudo parte da ideia de que há uma sensibilidade da gramática da criança para as proeminências acentuais do enunciado, como um movimento de direção centrípeta inicial para desencadear a aquisição fonológica, que norteará a estruturação silábica da palavra. Em seguida, entretanto, ocorre um movimento de direção oposta, centrífuga, partindo da sílaba acentuada, já produzida na fala, com todas as posições preenchidas ou não, para análises gramaticais que visam ao refinamento por meio do preenchimento segmental da sequência sonora de palavras, frases e enunciados da língua-alvo.

\section{Organização fonológica e as análises centrípeta-centrífuga}

A compreensão da inter-relação das unidades prosódicas e o acento que sustentam, auxiliando na segmentação, possibilitam explicar a aquisição fonológica como a identificação e o estabelecimento dos contrastes na língua. Defende-se aqui que todas as camadas prosódicas e as próprias características de sonoridade dos segmentos constituintes das sílabas arquivam informações sintetizadas de forma hierárquica e diferenciadas, iniciadas no enunciado fonológico. Essa unidade prosódica já foi abordada em pesquisas de aquisição fonológica no PB (SCARPA, 1997; SANTOS, 2001), como o início do processo a partir de proeminências entonacionais contidas no enunciado.

$\mathrm{Na}$ análise gramatical de direção centrípeta, a proeminência da unidade prosódica mais alta - o enunciado - conduz à sílaba nuclear entonacional. Acrescenta-se, contudo, a essa posição a ideia de que se desenvolve também uma direção de análise inversa, e possivelmente co-ocorrente, a direção centrífuga.

Assim, dessa sílaba mais proeminente, a unidade prosódica mais baixa na hierarquia, ocorre o preenchimento da cadeia sonora das sílabas vizinhas e dos seus segmentos constituintes, a fim de completar-se o pé métrico visando à palavra-alvo. A revisão das análises fonológicas centrífugas ocorre em camadas de níveis segmental e suprassegmental, influenciando os ajustes e confrontações distintivas.

Nas análises prosódicas centrífugas, evidenciam-se, portanto, operações fonológicas mais sofisticadas, envolvendo a constituição esqueletal das sílabas, as propriedades segmentais, as condições fonotáticas específicas e os níveis prosódicos superiores à sílaba e ao pé métrico - a palavra e as associações entre as palavras. Acima do nível da palavra e alcançando o enunciado, são consideradas também informações referentes à morfossintaxe desse nível prosódico.
Nessa hipótese de processamento gramatical de direção centrípeta inicial e de preenchimento de direção centrífuga, caracterizado por operações fonológicas mais refinadas quanto às informações que devem ser consideradas, está implícita a base hierárquica nas relações entre as estruturas constituintes, pressuposto defendido nas ditas fonologias autossegmental (GOLDSMITH, 1995; CLEMENTS; HUME, 1995) e prosódica (NESPOR; VOGEL, 1986), bases teóricas aqui assumidas para fundamentar as discussões nas análises dos dados.

As tarefas de segmentação do enunciado fonológico, sob efeito do acento entonacional no movimento de análise de direção centrípeta, e o preenchimento segmental, também sob efeito do acento, agora atuando numa direção centrífuga, que parte da sílaba mais proeminente da palavra, envolvendo nesses movimentos as relações binárias de dominante/dominado entre os constituintes prosódicos, estabelecendo a relação forte $\mathrm{x}$ fraco ou vice-versa (BISOL, 2005, p. 254-255), acontecem em todos os níveis prosódicos. Essa disposição da hierarquia prosódica de Nespor e Vogel (1986) e a relação binária forte $\mathrm{x}$ fraco entre os constituintes prosódicos comentada por Bisol (2005) favorecem a organização das unidades gramaticais. Essa organização das unidades viabiliza a estruturação do foco proeminente do input e desencadeia os movimentos de segmentação de direção centrípeta no enunciado e o preenchimento de direção centrífuga iniciado na sílaba mais proeminente - a sílaba foco ambos acionados pelo acento.

Logo, o enunciado fonológico do input mobiliza a gramática interna para dar início, de alguma forma, à segmentação desse todo - o enunciado -, ativando a interpretação fonológica para o constituinte foco e viabilizando as tarefas de derivações para gerar o output fonológico e por fim as possibilidades da realização fonética pelo aparato vocal. Possivelmente, esse constituinte será representado pela sílaba acentuada, que desencadeará as análises fonológicas em níveis segmental e fonotático. Desse modo, o que se observa ao nível da realização fonética de uma única sílaba emitida pela criança associada a uma palavra representa um somatório de derivações gramaticais que se processaram na sua organização mental.

O efeito da ação centrípeta é o de sinalizar o acento entonacional localizado numa determinada sílaba do enunciado, convergir para essa sílaba proeminente, considerada como uma unidade central, e por fim segmentá-la do enunciado. Assim, a sílaba é o ponto de atração da ação centrípeta, que converge para a proeminência. É desse recorte de sílaba que, numa segunda instância, ocorrem os preenchimentos, agora agindo sob efeito da ação centrífuga, realizando um 
sentido divergente que desencadeia os preenchimentos de material fonológico a partir da sílaba proeminente, inserindo segmentos nas posições silábicas tônicas e, em seguida, nas átonas vizinhas, incluindo a entrada de novos segmentos mediante a especificação de traços marcados, ou fornecendo o molde silábico inicial para as átonas.

Segue a Figura 1, elaborada por Payão (2010, p. 20), representando a atuação do movimento do acento na sílaba proeminente sob efeito das ações centrípeta e centrífuga, sendo essa sílaba o eixo referencial para a organização fonológica inicial da aquisição defendida na presente pesquisa.

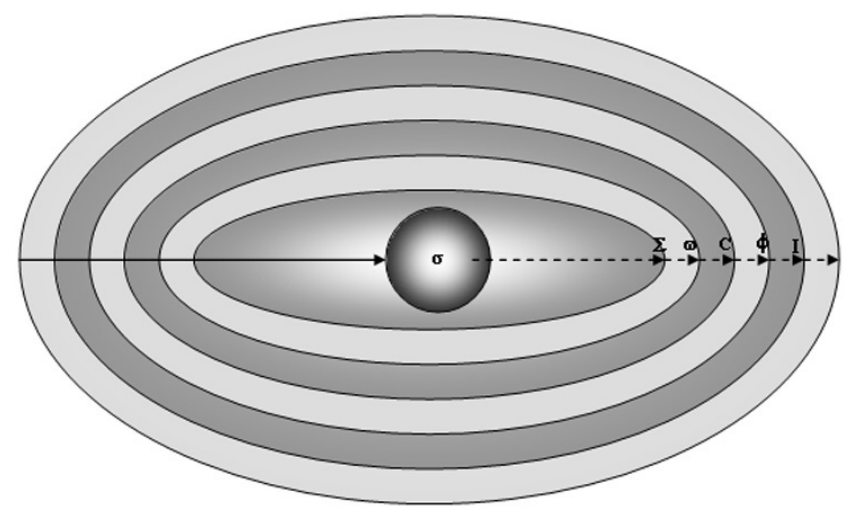

Figura 1. Representação esquemática dos movimentos do acento nas direções centrípeta e centrífuga, relacionados, respectivamente, à segmentação do enunciado (seta contínua) e ao preenchimento da sequência fonológica a partir da sílaba proeminente (setas tracejadas), elaborada por Payão (2010, p. 20).

Considera-se que o enunciado fonológico é captado na gramática interna, ou seja, é captado previamente - pelo menos parcialmente -, para que desencadeie a análise de direção centrípeta guiada pela sílaba detentora da proeminência.

A representação esquemática dos movimentos centrípeto-centrífugo do acento na aquisição prosódica em disposição gradativa de sucessivas elipses expressa a atração inicial convergente para a sílaba proeminente, que se origina de material fonológico maior - o enunciado -, constituído por todas as unidades prosódicas menores numa sequência hierárquica, conforme a fonologia prosódica de Nespor e Vogel (1986). As elipses representam os diferentes domínios da hierarquia prosódica, a seta contínua representa a segmentação do enunciado e a seta tracejada, os preenchimentos. A sílaba acentuada resultante da segmentação é considerada o ponto de partida para os preenchimentos segmentais. O movimento centrípeto - que segmenta material linguístico prévio implica o centrífugo - que preenche conforme a estrutura da língua. No sentido de complementação de tarefas para efetivar a aquisição fonológica, esses dois movimentos estão interrelacionados e possivelmente ocorrem simultaneamente. As setas tracejadas simbolizam o movimento de atração inversa - o centrífugo -, no qual os preenchimentos da sequência fonológica são graduais até alcançarem o enunciado. Esses preenchimentos acionados pela ação do acento no movimento centrífugo são representados por setas tracejadas, haja vista serem passíveis de revisão e reanálises na gramática interna durante a fase de aquisição.

Jakobson (1972) já salienta as funções do acento, primariamente com fins comunicativos, delimitando as tarefas precursoras na segmentação do enunciado, que refletem a estrutura hierarquicamente organizada da língua.

De acordo com a fonologia prosódica de Nespor e Vogel (1986, p. 249) e Nespor et al. (2008, p.1-3) há informações sintáticas relevantes nos constituintes fonológicos contidos nos sinais de fala, destacando, então, o papel perceptual auditivo para desencadear as tarefas compreensivas na gramática. Nesse sentido, é atribuído um papel prévio norteador para as habilidades perceptuais auditivas, identificando e reconhecendo as pistas prosódicas que sinalizam a sintaxe da língua a fim de que a segmentação do enunciado em palavras possa dar início, acessando, então, a sílaba proeminente e a sua constituição. À medida que a criança está exposta a língua materna, o primeiro contato com a ordem sintática é estabelecido pelas pistas prosódicas (NESPOR et al., 2008, p. 2-3).

A relevância do enunciado como o gatilho para orientar a criança em aquisição para a sintaxe da sua língua materna possibilita a análise fonológica de direção centrípeta que delimita a sílaba proeminente. É nessa perspectiva que a sílaba proeminente, resultante da segmentação, assume as características representativas de unidade prosódica superior - o enunciado. O recorte silábico geralmente é proveniente de constituinte sintático relevante na hierarquia sintática e sinalizado pelas pistas prosódicas.

\section{Metodologia}

O presente estudo observacional e descritivo investigou a interação entre o acento e o preenchimento segmental das unidades prosódicas inferiores - sílaba, pé e palavra, baseando-se nas produções de fala espontânea de duas crianças em aquisição do PB falado em Alagoas e Pernambuco, mais especificamente nas cidades de Maceió e Recife, entre 1;0.4 e 2;1.10 de idade.

A inclusão das crianças nesta pesquisa foi precedida de aprovação do projeto pelo CEP - UFAL, conforme processo de no 006680/2008-81 em 30 de junho de 2008, e de autorização de seus responsáveis mediante o Termo 
de Consentimento Livre e Esclarecido. Realizaram-se gravações em áudio digital das crianças em interações lúdicas com os pais durante trinta minutos, com intervalos mensais e estendendo-se por sete meses.

As análises fonológicas empreendidas nos dados fundamentaram-se no modelo prosódico de Nespor e Vogel (1986), relacionados aos níveis inferiores da hierarquia prosódica - sílaba, pé métrico e palavra -, e ao nível segmental, no Modelo Implicacional de Complexidade de Traços - MICT de Mota (1996), que explica a aquisição consonantal do português brasileiro à luz da fonologia autossegmental expressa no modelo universal da Geometria de Traços de Clements e Hume (1995).

As descrições situam-se, então, a partir da sílaba segmentada previamente pela análise gramatical, nas posições da estrutura silábica manipuladas, na formação do pé métrico, considerado no início da aquisição como forma de palavra reduzida mais semelhante ao alvo, e por último na palavra. No nível segmental, o estudo considerou a expansão do sistema de distinções dos sons da língua mediante as especificações de traços marcados.

\subsection{Os sujeitos da pesquisa}

As duas crianças, designadas como Sujeito 1 (S1) e Sujeito 2 (S2), são filhas de pais pernambucanos que residem e trabalham em Maceió há alguns anos, embora mantenham contato frequente com a cidade natal Recife -, quando visitam seus familiares. A proximidade geográfica entre os estados de Alagoas e Pernambuco e os vínculos familiares promovem nos sujeitos desta pesquisa o contato com os dialetos dessas duas capitais de estados contíguos da União. As características socioeconômicas e culturais das duas famílias são semelhantes, sendo ambas as crianças a primeira filha de cada casal.

Notam-se características comuns na fala das duas crianças, tanto a tendência de produção das vogais médias abertas - tendência esta típica do nordeste -, como a predominância da palatalização de coronal em coda, mais específica do dialeto recifense. Considerou-se, então, que a aquisição fonológica dessas crianças recebe influências diversificadas do PB falado.

Realizou-se anamnese fonoaudiológica descartando-se no relato dos pais a possibilidade de intercorrências orgânicas e/ou sócio-afetivas influenciando o desenvolvimento motor, cognitivo e linguístico dos sujeitos, ou algum comprometimento que necessitasse de encaminhamento para outro profissional da área da saúde para avaliações pertinentes.

Quanto à acuidade auditiva - fundamental para a aquisição fonológica -, ambas as crianças, quando recémnascidas, se submeteram à Triagem Auditiva Neonatal (TAN) por meio do teste de emissões otoacústicas e da pesquisa do reflexo cócleo-palpebral (RCP), nos quais obtiveram respostas presentes bilateralmente.

\subsection{0 corpus para as análises}

Transcreveram-se as palavras produzidas de forma nítida e recorrente durante o intervalo da gravação, sem restar dúvida ao interlocutor quanto à palavra utilizada pela criança no momento de suas emissões, a fim de confirmar-se como fazendo parte de seu léxico.

As palavras transcritas, seguindo esses critérios de inclusão, foram classificadas quanto ao número de sílabas, ao tipo de estrutura silábica manipulado, aos segmentos presentes e discriminados em relação à posição silábica tônica e às átonas pré-tônica e pós-tônica produzidas que visavam à efetividade da palavra-alvo.

Quanto aos segmentos consonantais predominantes nessas sílabas, relacionaram-se os traços distintivos já presentes no sistema fonológico, segundo a hierarquia de aquisição dos traços consonantais para o PB de Mota (1996).

Notou-se que tanto S1 como S2 repetiram palavras ou as construções de sintagmas verbais, que haviam sido pronunciadas pelos pais no momento imediato da interação. Portanto, realizaram segmentações dos enunciados dos pais, numa análise de direção centrípeta, introduzindo-as como falantes iniciais de sua língua materna.

\section{Análise descritiva: domínio do acento e os preenchimentos de camada prosódica e dos traços segmentais}

A expansão do inventário fonológico amplia as possibilidades prosódicas de construção das sílabas, a extensão das palavras e, consequentemente, as combinações de palavras para formar sentenças conforme a aquisição progride.

A sílaba acentuada parece influir nos segmentos que devem ocupar as posições silábicas vizinhas. Pode haver seleção de um mesmo segmento da sílaba acentuada que é compartilhado com outra vizinha ou os segmentos dessas sílabas contíguas constituem-se de um ou mais traços em comum.

Observam-se esses comportamentos nos dados de aquisição inicial, que se manifestam em processos de harmonia consonantal nos quais há preservação de alguma semelhança entre os segmentos, parecendo um processo facilitador para a produção nessa fase da criança.

\subsection{Análise e descrição dos dados - S1}

\section{$\mathrm{S} 1-1 ; 5 \quad$ (total $=8$ palavras $)$}

- Estruturas silábicas CV, V e CVG: monossílabos tônicos e constituintes binários, pés iâmbicos 
- dissílabo oxítono, presença de ditongos decrescentes [aw], [aj] e [Ew], vogais-base /a/ e /E/, sequência de aquisição desses ditongos segundo Bonilha (2004, p. 127):

\section{['tew] Téo [a.'ki] aqui}

- Palavras reduplicadas:
[paj.'paj] papai
[fo.'fo] vovó
[aw.aw.aw] аиаиаи
[ko.'ko] cocó (galinha)

- Sílaba acentuada: maior número de segmentos consonantais e vocálicos;

- Segmentos predominantes: plosivas e nasais $[\mathrm{p}, \mathrm{t}, \mathrm{m}] \rightarrow$ estágio inicial, traços não marcados, segundo a GU (MOTA, 1996; 2007); constatada a 1므 fricativa, labial [-voz], traço [+cont];

- Meta: compor os padrões binários de palavra mínima.

Segue a Tabela $1-\mathrm{S} 1-1 ; 5$ discriminando os segmentos utilizados nas sílabas átona pré-tônica, tônica e átona pós-tônica, conforme a inserção na sequência silábica das palavras produzidas na sessão:

Tabela 1. Inventário segmental das sílabas conforme a posição acentual nas palavras, $\mathbf{S} 1-1 ; 5$

\begin{tabular}{|c|c|c|c|c|c|c|c|c|c|c|}
\hline $\mathrm{S} 1-1 ; 5$ & \multicolumn{3}{|c|}{ Átona pré-tônica } & \multicolumn{4}{|c|}{ Tônica } & \multicolumn{3}{|c|}{ Átona pós-tônica } \\
\hline \multirow{5}{*}{$\mathrm{S} 1-1 ; 5$} & $\mathrm{C}_{1} \mathrm{C}_{2}$ & $\mathrm{~V}$ & $\mathrm{C}_{3}$ & $\mathrm{C}_{1} \mathrm{C}_{2}$ & $\mathrm{~V}$ & G & $\mathrm{C}_{3}$ & $\mathrm{C}_{1} \mathrm{C}_{2}$ & $\mathrm{~V}$ & $\mathrm{C}_{3}$ \\
\hline & $f(v)$ & 0 & & $f(v)$ & 0 & & & & & \\
\hline & $\mathrm{t}$ & a & & k & $\mathrm{i}$ & & & & & \\
\hline & $\mathrm{p}$ & & & $\mathrm{p}$ & a & $w, j$ & & & & \\
\hline & & & & $\mathrm{t}$ & $\varepsilon$ & & & $\mathrm{m}$ & I & \\
\hline Totais: & 030 & 02 & 0 & 040 & 04 & 02 & 0 & 010 & 01 & 0 \\
\hline
\end{tabular}

- Presença de pé binário: $\sigma$ tônica $+\sigma$ átona (prétônica)

- Segmentos menos marcados quanto aos traços, localizados num articulador específico (MOTA, 2007): favorece a realização;

- Preservação da sílaba tônica, com segmentos menos marcados, favorecem o preenchimento das sílabas:

['o:], ['bo] acabou

\section{S1 $-1 ; 6.15 \quad$ (total $=27$ palavras $)$}

- Reduplicações: menor complexidade no início da aquisição, tendência universal de produzir a palavra mínima, prevalência de formas de iambos no PB, corroborando com Santos (2001) e Baia (2008; 2009):

[mə.'məj] mamãe

[vo.'fo] vovó

[du.'du:] vrumm (onomatopeia)

[bi.'bi.t]I] 'bibiti' = motoca
S1 $-1 ; 7.16 \quad$ (total $=29$ palavras)

- Segmentos consonantais e vocálicos diferenciados em palavras paroxítonas, as sílabas tônica e póstônica são mais próximas à palavra-alvo:

\section{['bo.lə] bola}

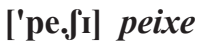

['ka.v] carro

- Tentativas de esboços de palavras trissílabas, oscilações entre formas binárias iâmbica ou trocaica:

['i:sı] Alice

[kə.'ej], [ko.'Kew], ['ke.î], [ku.'e.î] coelho

- Obstruintes plosivas: contraste entre os traços [labial], [coronal] e [dorsal]

['pĩ:.to] pinto

['pe.to] preto

[gwa.'da] guardar

- Sílaba pós-tônica: presença das líquidas laterais [ \pm anterior]

S1 $-1 ; 8.18 \quad($ total $=39$ palavras $)$

- Análises gramaticais: classe do segmento (combinação de traços marcados) e complexidade silábica:

['nãw], ['ãw], ['aw], [lo.'aw:] leão

[๘.'la.fa], [ə.'la.fa], ['la.fa] girafa

'ko.d3I] esconde

[a.'su:] azul

['la] lápis

['pa.ja] praia

- Predomínio: dissílabos e trissílabos paroxítonos, depois da tônica há maior número de preenchimentos segmentais consonantais no onset da pós-tônica, influência do input quanto às formas trocaicas;

S1 1 1;9.20 $\quad($ total $=41$ palavras $)$

- Manipulação de sequência silábica mais longa: trissílabos, $1^{a}$ polissílaba, paroxítonos, tendência a não realizar a sílaba pré-tônica, presença de truncamentos reduzindo a palavra ao pé binário (troqueu) com segmentos correspondentes;

[pa.sa.'i.lo], [pa.sa.'li.jo], [pa.sa.'li:.no], [pa.sa.'i:.jo], ['li.jo] passarinho

[ə.'kã.no], ['kã.na], [t fı.'kã.no], ['kã.no] tucano

- Coda: posição final, monossílabos, fricativa $/ \mathrm{s} /$. Precedência das vogais /e,o,a/ $\rightarrow$ contexto propício, de acordo com Mezzomo (2004, p, 144).

['dos] dois ['tes] três ['sej] seis ['dzs] dez $(1 ; 9.20)$ 
Tabela 2. Inventário segmental das sílabas conforme a posição acentual nas palavras, S1 - 1;9.20

\begin{tabular}{|c|c|c|c|c|c|c|c|c|c|c|}
\hline & Sílaba acento secundário & \multicolumn{2}{|c|}{ Átona pré-tônica } & \multicolumn{4}{|c|}{ Tônica } & \multicolumn{3}{|c|}{ Átona pós-tônica } \\
\hline & $\mathrm{C}_{1} \mathrm{C}_{2} \vee \mathrm{C}_{3}$ & $\mathrm{C}_{1} \mathrm{C}_{2}$ & $\mathrm{~V} \mathrm{C}_{3}$ & $\mathrm{C}_{1} \mathrm{C}_{2}$ & $\mathrm{~V}$ & $\mathrm{G}$ & $\mathrm{C}_{3}$ & $\mathrm{C}_{1} \mathrm{C}_{2}$ & $\mathrm{~V}$ & $\mathrm{C}_{3}$ \\
\hline \multirow[t]{9}{*}{ S1 - 1;9.20 } & $\begin{array}{ll}\mathrm{p} & \mathrm{a}\end{array}$ & $\mathrm{p}$ & $a, a ̃$ & $p, b$ & $\mathrm{a}, \mathrm{a}$ & $w, j$ & & $\mathrm{t}$ & $\mathrm{a}$ & \\
\hline & $\mathrm{a}(\mathrm{de})$ & $\mathrm{t} \int(\mathrm{t})$ & $\mathrm{i}, \mathrm{e}$ & $\mathrm{t}, \mathrm{d}$ & $e, i$ & & $\mathrm{~s}$ & $\left(\mathrm{t} \int\right)$ & $\mathrm{i}, \mathrm{I}$ & \\
\hline & & $\mathrm{k}$ & $0, \varepsilon$ & $(\mathrm{t} f)$ & $\varepsilon, 0$ & & & k & ə & \\
\hline & & $\mathrm{m}$ & $\partial$ & $\mathrm{k}$ & & & & $\mathrm{m}, \mathrm{n}$ & $v$ & \\
\hline & & $\mathrm{m}(\mathrm{b})$ & & $\mathrm{m}, \mathrm{n}$ & & & & $\mathrm{n}$ & & \\
\hline & & 1 & I & $v, f$ & & & & $\mathrm{~s}, \mathrm{z}$ & & \\
\hline & & $v$ & & $\mathrm{~s}, \int$ & & & & 1 & & \\
\hline & & $\mathrm{s}$ & & $\mathrm{I}(\mathrm{r})$ & & & & $\kappa(\mathrm{I})$ & & \\
\hline & & & & & & & & $\mathrm{I}(\mathrm{n})$ & & \\
\hline Totais: & $\begin{array}{llll}01 & 0 & 01 & 0\end{array}$ & 070 & $08 \quad 0$ & 120 & 06 & 02 & 01 & 090 & 05 & 0 \\
\hline
\end{tabular}

A Tabela 2 acima corresponde aos dados segmentais e de estruturas silábicas da sétima sessão de registros dessa criança, com 1;9.20.

Constata-se a presença de todos os segmentos vocálicos e consonantais do PB nos dados de S1 $(1 ; 8.18$ e 1;9.20), ainda ausentes as líquidas não laterais, que se estabelecem numa etapa posterior da aquisição mediante o contraste do traço [ \pm lateral].

\subsection{Análise e descrição dos dados - S2}

S2 $-1 ; 6.3 \quad$ (total $=12$ palavras)

- Forma binária com reduplicação, palavras trissílabas, troqueu e iambo:

[bo.'bo], [bi.'e.ta] borboleta, [ta.ba.'ja] trabalhar, [bĩ.'ke.do] brinquedo

\section{S2 $-1 ; 6.18 \quad$ (total $=18$ palavras)}

- Padrão CV, plosivas, nasais e fricativas [lab] e [cor]:

['vẽ] vem

['i.jo] isso

['pa.jo] pássaro

[pa.'fi.jo] passarinho

['fu.va] chuva

- Fricativas: nas sílabas tônica e pós-tônica, na tônica e pré-tônica, observam-se assimilação do traço [lab], presença do contraste $[ \pm \mathrm{voz}] \mathrm{e}$ harmonia vocálica:

['fu.va] chuva

[fe.'ẽ.do] chovendo

- Pé binário: compartilhar os segmentos no preenchimento silábico, preparar a inclusão da $3^{a}$ sílaba, inicialmente com plosivas e nasais, menos complexas;
S2 $-1 ; 6.28 \sim 1 ; 7 \quad$ (total $=36$ palavras $)$

- Pé troqueu: tendência do preenchimento da $\mathrm{s}$ pós-tônica, em seguida a pré-tônica, quantidade e qualidade de consoantes na tônica e pós-tônica são semelhantes, compartilham os traços:

[']u.fa] chuva

['pe.fi] peixe

[ka.'zi.na] casinha ['e.бI] esse $\quad(1 ; 6.28 \sim 1 ; 7)$

\section{S2 $-1 ; 8.9 \quad($ total $=71$ palavras $)$}

- Diferenciação de vogais é maior na tônica, diferenciação maior de consoantes na pós-tônica: funções dos segmentos vocálicos e consonantais na definição do pé métrico;

- Presença de dissílabos e trissílabos, segmentos mais marcados quanto aos traços:

/f, $\mathbf{v}, \mathbf{s}, \mathbf{z}, \int, \mathbf{3}, \mathbf{h} / \rightarrow[+\mathbf{c o n t} / \pm \mathbf{v o z}]$;

- Semivocalização das líquidas, tentativa de preencher onset complexo:

[ka.'va.lo] [ka.'va.jo] cavalo ['ko.bja] cobra [a'go.ja] agora

[ke.'bjo] quebrou

[ve.'me.jo] vermelho

\section{S2 $-1 ; 9.25 \quad$ (total $=36$ palavras)}

- Presença de polissílabas paroxítonas, preenchimento mínimo do núcleo silábico ou semivocalização de líquida [ \pm lateral]:

[te.e.'fo.nI] telefone

[ta.ta.'ju.ga] tartaruga

[di.i.'go] desligou

['li.go] ligo (ligar)

\section{S2 $-1 ; 11.15 \quad($ total $=126$ palavras $)$}

- Acento primário + acento secundário: manutenção do ritmo alternante $\rightarrow \mathrm{s}$ forte $\mathrm{X} \mathrm{s}$ fraca, expansão prosódica e segmental:

[bo.bo.le.'tfi.ja] borboletinha 
- Aquisição de traços segmentais favorecida na tônica e na pós-tônica, relacionado ao pé métrico, influência do input:

\section{[ə.'fã.tf I] elefante}

[a.ma.'le.lo], [ma.'le.lo] amarelo

- Líquida não lateral, /R/ - 'r-forte' $\rightarrow$ [h], ambiente fonológico, pós-tônica e tônica com vogal /o/, em onset (MEZZOMO; RIBAS, 2004, p. 106):

[ka.'fEo.ho] cachorro [o.'dã.dv] rodando $(1 ; 11.15)$

- Coda: inicialmente, em monossílabos, fricativa coronal, posição final:

['doj], ['doj]] dois

['tfif] três

\section{S2 $-2 ; 1.10 \quad$ (total $=149$ palavras)}

- Sílaba tônica e o pé métrico: sob a ação centrífuga, preenchimentos:

$\begin{array}{ll}\text { ['hu.a] rua } & \text { ['ho.da] roda (verb. rodar) } \\ \text { ['ha.to] rato } & \text { [bo.ja.'Ji.jna] borrachinha }\end{array}$

- Palatalização da coda, variante PE:

['dewf] Deus /s/ $\rightarrow\left[\int\right]$

- Expansão segmental, inclusão das laterais, início da estrutura silábica CCV - onset complexo:

['ble.no] Breno

['ko.bla] cobra

[mi.'jã], [mi.'אã], [mi._î.'ã] Miriam

- Abrangência de classes gramaticais, combinação de duas palavras - sintagmas nominais e verbais, aprimoramento fonológico.

\section{Confluência de informações fonológicas: do acento, da sílaba e dos traços segmentais}

Os recortes de fala realizados por S1 e S2 são regidos por acentos de natureza diferente, como afirmam Scarpa (1999a; 1999b) e Santos $(2001 ; 2003 ; 2007)$ em suas pesquisas, resultantes de uma análise linguística global do sintagma entonacional, ou seja, da unidade prosódica superior - o enunciado. A primeira influência sonora do acento de proeminência entonacional compõe-se de contornos melódicos expressos por tons de movimentos ascendente $(\mathrm{H}$ - alto) e descendente ( $\mathrm{L}$ - baixo) (SANTOS, 2001, p. 69-72).

À medida que adquire as regras gramaticais de acentuação ao nível da palavra, identificando, então, as sílabas que a compõem e seus segmentos correspondentes com caráter distintivo, a criança inicia, então, a trabalhar com o acento lexical específico.
Quando ela executa os processos fonológicos de ressilabificação e reestruturação das palavras que compõem seus enunciados ainda reduzidos a uma ou duas palavras, as análises gramaticais que se realizam são as de direção oposta, centrífuga - desencadeando progressivamente os preenchimentos segmentais que se originaram a partir da unidade prosódica inferior - a sílaba.

A ação centrífuga na sílaba tônica preenche com segmento tanto a sílaba pós-tônica quanto a pré-tônica, em conformidade com o pé métrico da palavra-alvo. Constatou-se, inicialmente, a influência do padrão troqueu frequente no $\mathrm{PB}$, como levantado em estudos da fonologia dessa língua. Nas duas crianças acompanhadas houve a tendência para o preenchimento e a diferenciação de classes segmentais nas posições silábicas tônica e póstônica.

Considera-se também que os movimentos de análise fonológica centrípeto-centrífuga se desenvolvem a partir dessa interação entre o acento versus sílaba durante a aquisição. Dessa atuação conjunta dispara-se, então, a aquisição segmental necessária para preencher as posições silábicas, conforme a escala de sonoridade dos segmentos de Clements e Hume (1995, p. 268-269).

Segundo essa escala de sonoridade os segmentos são classificados em grandes classes - obstruintes, nasais, líquidas e vocoides - a partir da unidade dos traços de raiz - [sonorante], [aproximante] e [vocoide] -, com a função de definir o grau de sonoridade nessas classes de segmentos (CLEMENTS; HUME, 1995, p. 269).

Entre as tarefas de adquirir uma língua, a identificação do acento, ainda que no nível da frase, prepara a criança para perceber diferenciações na sequência da fala do input num refinamento crescente. A prosódia tem sido apontada por Scarpa $(1997,1999 b)$ e Santos $(2001,2007)$ como a sinalizadora para as segmentações do enunciado, e realiza intercâmbio mais estreito entre os componentes semântico e morfossintático.

Mediante a percepção do acento, a criança inicia a estruturação prosódica, tornando-se capaz de compreender o input e organizar os ensaios dos seus primeiros enunciados. Esse 'enunciado' inicial de uma sílaba, como Scarpa (1999a, p. 274-279) salienta, mesmo sendo formado por uma única sílaba emitida num dado contexto, possui o valor de enunciado pela superposição de informação linguística contida nessa sílaba.

O preenchimento segmental da sílaba obedece aos critérios de sonoridade entre as consonantes e vogais, licenciadas para as posições específicas na estrutura silábica, de forma que concorram favoravelmente ao ritmo melódico por meio da alternância entre os sons, gerando assim a saliência perceptual na sequência sonora. 
A saliência perceptual inicial encontra-se no enunciado, que se materializa no acento captado no input e torna-se o guia para efetivar as segmentações desse enunciado. Geram-se, então, os recortes silábicos, que nesse ponto possuem o valor representativo de nível prosódico superior. A análise centrípeta é guiada pelo acento e mostra-se efetiva funcionalmente na percepção dos traços prosódicos e na segmentação dos sons da sílaba representativa do enunciado, auxiliando na delimitação das palavras e nos processos fônicos distintivos, como preconiza Jakobson (1972, p. 26).

A partir dessa etapa, podem-se explicar os preenchimentos pelo modelo da geometria de traços (CLEMENTS; HUME, 1995), que organiza a sequência interna dos traços dos segmentos e preenche a estrutura silábica eleita a mais proeminente, orientada, agora, pela direção de análise centrífuga completando o pé métrico, a palavra e assim sucessivamente com as unidades prosódicas superiores.

\section{Conclusões}

Os dados analisados de S1 e S2 permitem identificar análises fonológicas de direção centrípeta inicial, que localizam a unidade mais proeminente do enunciado. A partir dessa unidade prosódica, inicia-se a segmentação em sílabas, originando, então, a análise centrífuga seletiva na sílaba acentuada, tarefa complementar na interpretação fonológica, que visa ao preenchimento segmental e fonotático mais refinado. Essas operações fonológicas centrípeto-centrífugas se complementam, visando à forma-alvo e se originam de saliências perceptuais de caráter linguístico, que são impulsionadas a movimentarse no enunciado.

À medida que percebe a estrutura esqueletal da sílaba e as alternâncias entre os segmentos, inicia-se, então, a reconstrução do enunciado, sendo a energia proveniente da saliência perceptual localizada na sílaba o ponto de partida na construção do enunciado. Portanto, a sílaba origina o movimento de direção centrífuga nas análises de preenchimento segmental dos níveis prosódicos acima dela.

Constata-se que a aquisição de linguagem, quanto aos aspectos fonológicos, é influenciada pelo acento e pela organização hierárquica das unidades do sistema prosódico e do segmental em inter-relação com os demais sistemas gramaticais. As evidências mostram que as análises gramaticais da direção centrípeta partem de referenciais prosódicos, ainda sob efeito do enunciado fonológico; e preenchem na direção centrífuga com aspectos silábicos, métricos e segmentais.

Os fatos observados nos dados de fala dessas crianças em faixas etárias diferenciadas fornecem as manifestações de uma estrutura linguística em aquisição que obedece à hierarquia entre os constituintes e as tarefas a serem executadas.

\section{Referências}

BAIA, Maria de Fátima de A. Formato prosódico inicial na aquisição do português brasileiro e as implicações metodológicas. 2008. 167 p. Dissertação (Mestrado) Departamento de Linguística, Universidade de São Paulo, São Paulo.

BAIA, Maria de Fátima de A. A. As palavras reduplicadas na aquisição do português brasileiro. Livro de Resumos do $2^{\circ}$ Seminário de Aquisição Fonológica - Tema Aquisição fonológica: perspectivas atuais. Org. de G. F. Gonçalves. Faculdade de Letras/UFPel; PPGDCH-PPGL/UFSM, Santa Maria, 2009. p. 68-70.

BISOL, L. (org.). Introdução a Estudos de Fonologia do Português Brasileiro. 4. ed. rev. e ampl. Porto Alegre: EDIPUCRS, 2005. p. 243-255.

BONILHA, G. F. G. Sobre a aquisição do núcleo complexo. In: LAMPRECHT, R. R. (org.). Aquisição fonológica do português. Perfil de desenvolvimento e subsídios para terapia. Porto Alegre: ArtMed, 2004, p. 113-127.

CHOMSKY, N. O Programa Minimalista. Tradução, Apresentação e Notas à Tradução: Eduardo Paiva Raposo. Lisboa: Editorial Caminho, 1999.

CLEMENTS, G. N.; HUME, E. The internal organization of speech sounds. In: GOLDSMITH, J. (ed.). The Handbook of Phonological Theory. Cambridge: Blackwell, 1995. p. 245-306.

GOLDSMITH, J. A. Autosegmental and Metrical Phonology. London: Blackwell, 1995.

JAKOBSON, R. Fonema e fonologia - ensaios. Seleção, tradução e notas, com estudo sobre o autor, por J. Mattoso Câmara Jr. Rio de Janeiro: Livraria Acadêmica, 1972.

MEZZOMO, C. L. Sobre a aquisição da coda. In: LAMPRECHT, R. R. (org.). Aquisição fonológica do português. Perfil de desenvolvimento e subsídios para terapia. Porto Alegre: ArtMed, 2004. p. 142-146.

MEZZOMO, C. L.; RIBAS, L. P. Sobre a aquisição das líquidas. In: LAMPRECHT, R. R. (org.). Aquisição fonológica do português. Perfil de desenvolvimento e subsídios para terapia. Porto Alegre: ArtMed, 2004. p. 95-109.

MOTA, Helena B. Aquisição segmental do português: um modelo implicacional de complexidade de traços. 1996. $221 \mathrm{p}$. Tese (Doutorado em Letras) - Instituto de Letras e Artes, Pontifícia Universidade Católica do Rio Grande do Sul, Porto Alegre.

MOTA, Helena B. Modelo Implicacional de Complexidade de Traços - os caminhos na aquisição segmental do português. In: BONILHA, G. F. G.; KESKE-SOARES, M. (orgs.). Estudos em Aquisição Fonológica. Santa Maria: UFMS, PPGL - Editores, 2007. p. 123-136.

NESPOR, M.; VOGEL, I. Prosodic Phonology. Dordrecht: Foris Publications, 1986. 
NESPOR, M. et al. Different phrasal prominence realizations in $\mathrm{VO}$ and $\mathrm{OV}$ languages. Lingue e Linguaggio, v. VII, n. 2, p. 1-29, 2008.

PAYÃO, Luzia. Miscow da C. Aquisição de fonologia: a influência do acento e o preenchimento de unidades prosódicas em dados de fala de duas crianças entre 1;0.4 e 2;1.10 de idade, em contato com o português brasileiro falado em Alagoas e Pernambuco. 2010. 192 p. Tese (Doutorado em Linguística) Programa de Pós-Graduação em Letras e Linguística. Faculdade de Letras, Universidade Federal de Alagoas, Maceió.

SANTOS, Raquel. S. A aquisição do acento primário no português brasileiro. 2001. 316 p. Tese (Doutorado em Linguística) - Instituto de Estudos da Linguagem, Universidade Estadual de Campinas, Campinas.

SANTOS, Raquel. S. Estratégias para aquisição do acento primário em PB. Letras de Hoje, Porto Alegre, v.38, n. 1, p. 171-188, mar. 2003.

SANTOS, Raquel. S. O acento e a aquisição da linguagem em português brasileiro. In: ARAÚJO, G. A. de (org.). O Acento em Português - abordagens fonológicas. São Paulo: Parábola Editorial, 2007. p. 226-258.
SANTOS, R. S.; SCARPA, E. M. The phonological bootstrapping of determiners. Linguistics in the Netherlands, v. 22, n. 1, p. 165-178, 2005.

SCARPA, E. Learning external sandhi: evidence for a Topdown hypothesis of prosodic acquisition. In: SORACE, A.; HEYCOK, C.; SHILLCOCK, R. (org.). Proceedings of GALA 1997. Conference on Language Acquisition: Knowledge Representation and Processing, 1997. p. 272-277.

SCARPA, E. Sons preenchedores e guardadores de lugar: relações entre fatos sintáticos e prosódicos na aquisição de linguagem. In: SCARPA, E. (org.). Estudos de Prosódia. Campinas: Editora da UNICAMP, 1999a. p. 253-284.

SCARPA, E. Interfaces entre componentes e representação na aquisição da prosódia. In: LAMPRECHT, R. R. (org.). Aquisição da linguagem - questões e análises. Porto Alegre: EDIPUCRS, 1999b. p. 17-38.

Recebido: 03 de fevereiro de 2016. Aprovado: 02 de junho de 2016.

Contato: luziapayao@uol.com.br januafc@bol.com.br. 